\title{
A new link between diabetes and cancer: enhanced WNT/ $\beta$-catenin signaling by high glucose
}

\section{Custodia García-Jiménez, Jose Manuel García-Martínez, Ana Chocarro-Calvo and Antonio De la Vieja'}

Departamento de Fisiología y Bioquímica, Facultad de Ciencias de la Salud, Universidad Rey Juan Carlos, 28922 Alcorcon, Madrid, Spain

'Unidad Funcional de Investigación en Enfermedades Crónicas (UFIEC), Instituto de Salud Carlos III, 28220 Majadahonda, Madrid, Spain
Correspondence should be addressed to C García-Jiménez Email custodia.garcia@urjc.es

\begin{abstract}
Extensive epidemiological studies suggest that the diabetic population is at higher risk of site-specific cancers. The diabetes-cancer link has been hypothesized to rely on various hormonal (insulin, IGF1, adipokines), immunological (inflammation), or metabolic (hyperglycemia) characteristics of the disease and even on certain treatments. Inflammation may have an important but incompletely understood role. As a growth factor, insulin directly, or indirectly through IGF1, has been considered the major link between diabetes and cancer, while high glucose has been considered as a subordinate cause. Here we discuss the evidence that supports a role for insulin/IGF1 in general in cancer, and the mechanism by which hyperglycemia may enhance the appearance, growth and survival of diabetes-associated cancers. High glucose triggers several direct and indirect mechanisms that cooperate to promote cancer cell proliferation, migration, invasion and immunological escape. In particular, high glucose enhancement of WNT/ $\beta$-catenin signaling in cancer cells promotes proliferation, survival and senescence bypass, and represents a previously unrecognized direct mechanism linking diabetes-associated hyperglycemia to cancer. Increased glucose uptake is a hallmark of tumor cells and may ensure enhanced WNT signaling for continuous proliferation.

Mechanistically, high glucose unbalances acetylation through increased p300 acetyl transferase and decreased sirtuin 1 deacetylase activity, leading to $\beta$-catenin acetylation at lysine K354, a requirement for nuclear accumulation and transcriptional activation of WNT-target genes. The impact of high glucose on $\beta$-catenin illustrates the remodeling of cancer-associated signaling pathways by metabolites. Metabolic remodeling of cancer-associated signaling will receive much research attention in the coming years. Future epidemiological studies may be guided and complemented by the identification of these metabolic interplays. Together, these studies should lead to the development of new preventive strategies for diabetes-associated cancers.
\end{abstract}

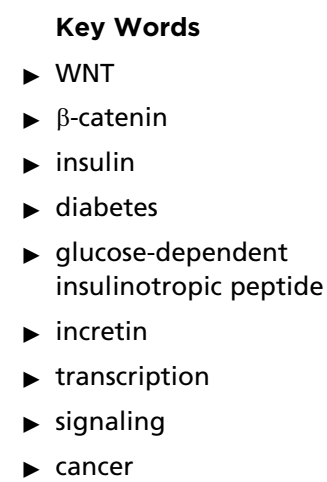

Journal of Molecular Endocrinology (2014) 52, R51-R66

\section{Introduction}

Extensive epidemiological studies have revealed that the diabetic population is at higher risk of suffering cancers of the liver, pancreas, endometrium, colon and others
(Shikata et al. 2013). Increased cancer risk in the diabetic population may be attributed to treatment for diabetes, to hormonal disorders, to the status of chronic inflammation 
and to metabolic alterations underlying the diseases (summarized in Fig. 1). Moreover, diabetes may also develop following tumor establishment in certain pancreatic and liver cancers that progress very rapidly (Li et al. 2012; Fig. 1, please note the double headed arrow representing the bidirectionality of the link). As, to our knowledge, there are very few studies that analyze this point separately, we do not explore it in this review. The impact of antidiabetic treatments on cancer risk is discussed elsewhere (Bowker et al. 2006, Jonasson et al. 2009, Dowling et al. 2012, Bosetti et al. 2013).

The major hormonal disorders in diabetes are unbalanced adipokine secretion, reviewed in Khandekar et al. (2011), and most important hyperinsulinemia and the associated increase in insulin-like growth factor 1 (IGF1) signaling. Hyperinsulinemia may arise in type 1 diabetes (T1D) from exogenous injection due to treatment, and in type 2 diabetes (T2D) it develops early in the disease as a physiological response to lower the increasingly high glucose levels in the blood. The mechanisms whereby hyperinsulinemia could link diabetes and cancer have been extensively reviewed, and are thought to be mediated mainly by increased bioavailability of IGF1 (Novosyadlyy \& LeRoith 2010, Djiogue et al. 2013). However, recent epidemiological studies demonstrate that circulating IGF1 levels do not correlate with tumor progression and report no relationship between IGF1 or IGF-binding protein levels and cancer risk (Kaplan et al. 2012).

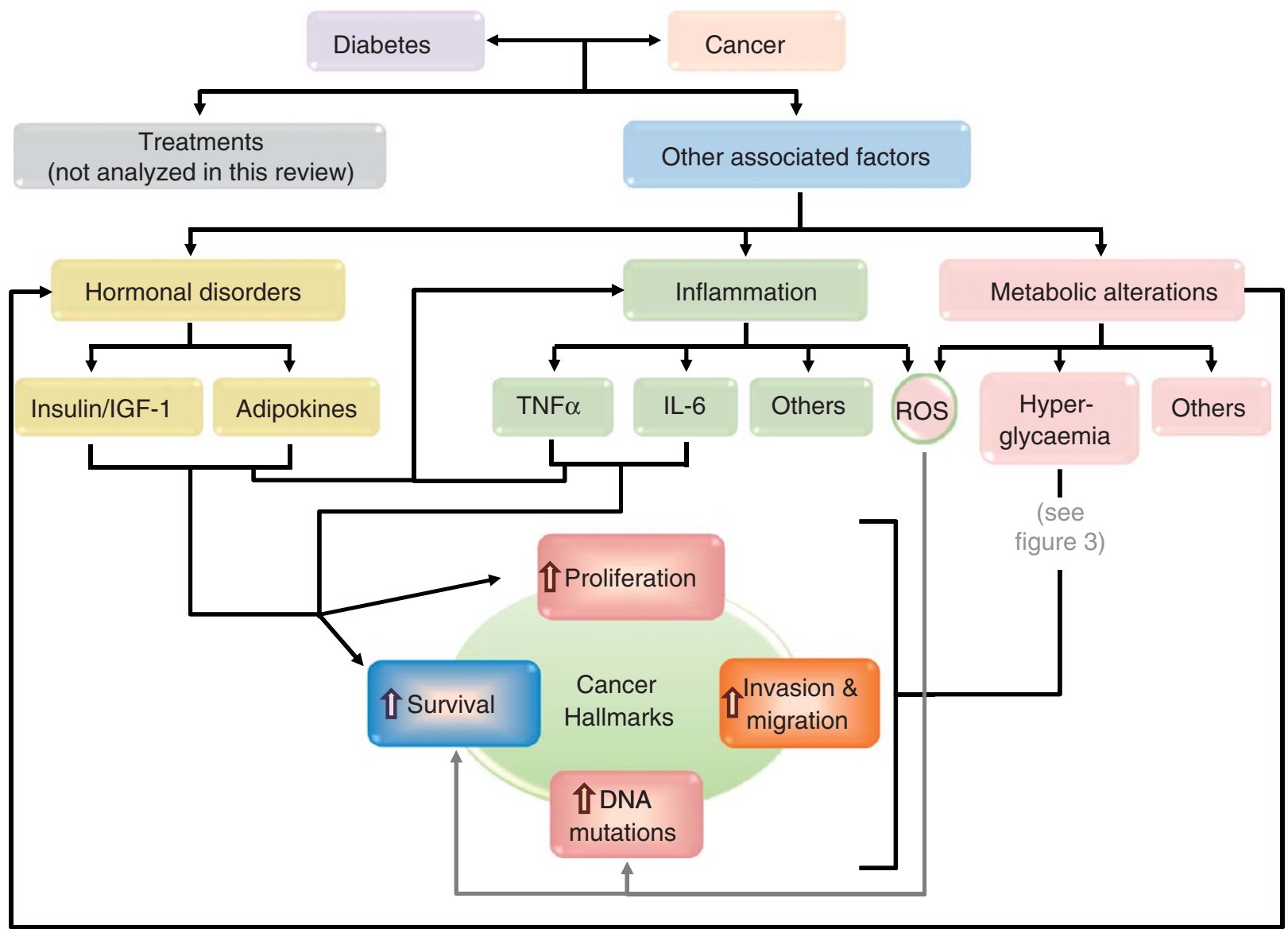

\section{Figure 1}

Links between diabetes and cancer. Diabetes and cancer are linked by a double headed arrow because the frequency of certain cancers is increased in the diabetic population and conversely certain cancer patients develop diabetes (see the text). The diagram shows a summary of mechanisms that may contribute to increased cancer risk in the diabetic population, that is i) some treatments which are not discussed in this review; ii) hormonal disorders such as increased circulating levels of insulin (endogenous or exogenous), and subsequent increase in insulin-like growth factor 1 (IGF1) signaling. Altered balances of some adipokines may also contribute to an Printed in Great Britain
C 2014 Society for Endocrinology inflammatory state and increased proliferation; iii) chronic inflammation characterized by increased circulating levels of tumor necrosis factor $\alpha$ (TNF $\alpha$ ), interleukin 6 (IL6), and others which have been described to underlie the diabetic state; iv) metabolic disturbances are represented mainly by hyperglycemia and accumulation of reactive oxygen species (ROS), both of which may induce secretion of proinflammatory cytokines and hormonal disorders, such as increased insulin secretion, and therefore both lead to increased proliferation and mutations. The effects of hyperglycemia are detailed in Fig. 3. For other details, see the text. 
Another aspect of the pathophysiology of diabetes and cancer is a shared status of chronic inflammatory signaling leading to insulin resistance (Grivennikov et al. 2010, Hummasti \& Hotamisligil 2010, Nakagawa \& Maeda 2012). Inflammatory cytokines signal through the mitogen-associated protein kinase: MAPK or JAK/STAT pathways, and contribute to cancer biology through increased proliferation, survival, accumulation of mutations (Hoffmann \& Baltimore 2006, Parameswaran \& Patial 2010), and suppression of host antitumor immunity (Yu et al. 2009). However, although it seems clear that inflammatory cytokines play an important role in tumor growth and invasion, the inflammatory response may also have antitumor activity (Allavena \& Mantovani 2012, Haabeth et al. 2012). More studies are needed to clarify the contribution of the inflammatory response.

Diabetes-associated metabolic alterations such as increased circulating levels of lipids and sugar represent another link with cancer. Lipid metabolism and signaling might play an important, though still incompletely understood, role in cancer which has been recently covered by Natter \& Kohlwein (2013). The analysis of the influence of lipids on diabetes-associated cancers is beyond the scope of this review. Hyperglycemia is the best characterized metabolic alteration in all types of diabetes, and we discuss in this review the evidence and molecular mechanisms that may associate hyperglycemia with cancer (Giovannucci et al. 2010, Wang et al. 2013). Hyperglycemia links diabetes and cancer indirectly through the induction of increased circulating levels of growth factors (insulin/IGF1) and inflammatory cytokines, but hyperglycemia also acts directly upon tumor cells. Among the direct actions on cancer cells, a relatively unexplored aspect is the influence of high glucose levels on cancer signaling. In this context, high glucose has been shown to be essential for WNT/ $\beta$-catenin signaling, a key cancer-associated pathway (Anagnostou \& Shepherd 2008, Chocarro-Calvo et al. 2013). As such, amplified $\mathrm{WNT} / \beta$-catenin signaling represents a previously unrecognized link that may contribute to the higher frequencies of cancer in the diabetic population. Other examples of metabolic remodeling of cancer-related signaling are illustrated by enhanced MAPK and AKT cancer-related signaling through increased production of reactive oxygen species (ROS) via increased oxidative phosphorylation (OXPHOS) (Ray et al. 2012).

Mutations toward constitutive oncogene activation or loss of tumor suppressors have been viewed as initiating steps in cancer promotion (Hsu \& Sabatini 2008, Jones \& Thompson 2009), while metabolic changes have been considered as an adaptation or a consequence of such mutations. As such, a number of oncogenes including $R A S$ and $M Y C$ have been shown to alter the expression of many genes encoding metabolic enzymes critical for glycolysis, OXPHOS, etc. (Pylayeva-Gupta et al. 2011). Although this is undisputable, metabolic stress may also drive the acquisition of mutations for cancer promotion (Martinez-Outschoorn et al. 2013). Metabolic stress may be caused by excess nutrients (Wellen \& Thompson 2010) like hyperglycemia - in cells that are able to take them up but are incapable of storing them (the vast majority of our cells). In this respect, circulating levels of insulin or IGF1 will allow glucose uptake without the need for mutations. In this review, we provide an overview of the mechanisms that may link hyperglycemia to cancer with a special focus on those related to remodeling cancerassociated cell signaling.

\section{Hyperglycemia may feed cancer cells: the sweet kiss of death}

Over the last century, cancer patients have been reported to exhibit signs of early glucose intolerance and insulin insensitivity, most likely as a result of an acute phase inflammatory response induced by the tumor (Marat et al. 1999, Klement \& Kammerer 2011). On the other hand, enhanced glucose uptake is a well-known metabolic hallmark of cancer cells. Hyperglycemia could therefore ensure a high glucose supply for cancer cells favoring anabolic cancer metabolism to fuel tumor growth and thereby explain the increased cancer risk associated with diabetes. Thus the relationship between hyperglycemia and cancer appears bidirectional: cancer can cause hyperglycemia, and hyperglycemia may facilitate cancer appearance and growth.

Increased glucose flux and metabolism, maintained by angiogenesis, promotes cell cycle progression, excessive proliferation, and anti-apoptotic signaling in cancer cells. In vitro, in tumor cell lines from several organs (breast, colon, others), diabetogenic glucose concentrations alter the expression of genes that promote cell proliferation, migration, and adhesion (Masur et al. 2011). In vivo, in tumor-bearing animals, blood glucose levels strongly correlate with tumor growth. Certain experimental cancers behave more aggressively when animals overeat, and less aggressively when animals are calorically restricted (Algire et al. 2008, Kalaany \& Sabatini 2009, Park et al. 2010), providing evidence that diet may influence neoplasia (Pollak 2009). Indeed, animals fed a calorie-restricted diet

Published by Bioscientifica Ltd. 
show a strong reduction in plasma glucose levels and prolonged survival (Santisteban et al. 1985).

In humans, high sugar intake and elevated blood glucose levels are associated with increased cancer risk, with hyperglycemia being a predictor of poor survival (Krone \& Ely 2005, Derr et al. 2009). In large cohort studies, hyperglycemia is positively correlated to an increased risk of developing cancers associated with the gastrointestinal tract (Jee et al. 2005, Stattin et al. 2007, Ikeda et al. 2009). A diet which repeatedly elevates blood glucose levels due to a high glycemic load has been suggested to provide additional growth stimuli for neoplastic cells (Mulholland et al. 2008, Masur et al. 2011).

Increased demands for glucose by cancer cells and the positive correlation between cancer risk and hyperglycemia, as in T1D and T2D, may not be a coincidence. Thus, hyperglycemia should not be neglected as a potential underlying factor facilitating cancer growth and/or establishment.

\section{Hyperglycemia vs hyperinsulinemia as a cancer-diabetes link}

Although impaired glucose tolerance, without diabetes, is associated with increased cancer risk (Dankner et al. 2007), hyperglycemia inexorably induces increased insulin secretion unless there is a defect in insulin production or secretion. Hyperinsulinemia develops early in T2D patients in response to hyperglycemia and may also be present in T1D patients after exogenous injection of insulin. As insulin acts as a growth factor, hyperglycemia has been classically considered as a subordinate and hyperinsulinemia as the primary causative factors for cancer (Giovannucci 2001). Early attempts to clarify this point showed that tumor growth was retarded in animals with T1D (Heuson \& Legros 1972), suggesting that tumor growth relies on insulin and not on high glucose. However, the autoimmune nature of T1D may complicate the interpretation of this result, because the immune system plays a pivotal role in cancer cell surveillance (Allavena \& Mantovani 2012, Haabeth et al. 2012). In vitro studies also showed that adding insulin to the medium containing high glucose promoted the sequential activation of PI3K, AKT, and mTOR leading to the increased anabolic activity in cancer cells and subsequent $20-40 \%$ enhanced proliferation rates (Klement \& Kammerer 2011, Ward \& Thompson 2012). However, in these experiments, the effects of hyperinsulinemia and hyperglycemia could not be disentangled as both were present and the tissue culture medium contained high levels of glucose.
In vitro, activation of the receptors for insulin or IGF1 (IR and IGF1R respectively) increases proliferation and blocks apoptosis. This, together with the observation that cancer cells over express IRs and IGF1Rs supports the idea that insulin and IGF1 are important drivers of cancer cell growth. However these receptors appear to be over expressed in most solid and hematopoeitic tumors and are not specifically increased in those cancers associated with diabetes (Belfiore et al. 2009, Gallagher \& LeRoith 2011). Furthermore, targeting IGF1R with different inhibitors has been helpful only in small subsets of patients, reviewed in Chen \& Sharon (2013), although the failure of the treatment could be attributed in some cases to constitutive activation of the pathway. On the other hand, increased circulating levels of insulin or IGF1 have been reported in prostate cancer (Hellawell et al. 2002, Rowlands et al. 2012). Nevertheless, prostate cancer is less frequent in the diabetic than in the nondiabetic population (Kasper \& Giovannucci 2006). Moreover, some authors have reported decreased tumor growth after insulin treatment in diabetic animals (Fisher et al. 1995) or the successful treatment of some patients with metastatic tumors by an insulin-induced hypoglycemic coma (Koroljow 1962). Some authors even propose that insulin may help in antitumoral treatment by increasing membrane permeability to other drugs (Lasalvia-Prisco et al. 2004).

In contrast, high glycemic index or high glycemic load does correlate with the site-specific cancers associated with diabetes (Gnagnarella et al. 2008, Mulholland et al. 2009). Cancer cells upregulate glucose transporters (GLUTs) independently of insulin (Pollak 2008, Szablewski 2013), although insulin may further increase the exhibition of glucose transporter GLUT1 and glucose uptake with it in some cells (Cifuentes et al. 2011). The importance of high glucose for cancer growth and survival is supported by results obtained after glucose starvation. Malignant cells in vitro quickly lose ATP when starved of glucose (Demetrakopoulos et al. 1978, Priebe et al. 2011). Glucose starved cells commit apoptosis after toxic accumulation of ROS that results from a positive feedback loop including increased tyrosine kinase signaling (Graham et al. 2012). In animals bearing tumors (Zhou et al. 2007), and in human patients (Seyfried et al. 2009), lowering blood glucose with ketogenic diets to force mitochondrial use of ketones as energy sources restricts the amount of glucose available to cancer cells and improves or prolongs survival. Moreover, treatment with metformin, which decreases hepatic gluconeogenesis and reduces glucose release to the blood, improves cancer outcome (El-Mir et al. 2000, Dowling et al. 2012).

Published by Bioscientifica Ltd. 
However, metformin also has direct actions on cancer cells, some of them through induction of the metabolic sensor AMPK (Dowling et al. 2012, Hardie 2013).

Better-controlled experiments might help evaluate the relative importance of insulin and glucose. For example, tumor appearance and growth may be tested in animals with hyperglycemia induced in the absence of hyperinsulinemia or inflammation. In this respect, it is interesting to highlight that association of T1D with the diabetesspecific cancers is stronger than in T2D, even though hyperinsulinemia may play a more prominent role in $\mathrm{T} 2 \mathrm{D}$ (García-Jiménez et al., manuscript in preparation). Nevertheless, if exogenous administration of insulin in T1D is associated with cancers, it should be considered among the cancers associated with treatments for diabetes which appear to be even more site-restricted, for example to the bladder, kidney, and breast, but not to gastrointestinal tumors which are more strongly linked to T1D.

\section{Hyperglycemia contributes to the abnormal glucose metabolism in cancer cells}

Cancer cells originate from noncancer cells and exhibit very distinctive metabolic hallmarks (Hanahan \& Weinberg 2011). Senescence and apoptosis bypass coupled to higher proliferation rates and migratory capacity must be fed. Enhanced angiogenesis in response to factors secreted by the tumor drives the genesis of new blood vessels that increase the supply of energetic substrates and building blocks needed to make new cells. Proliferative and resting cells differ more in their demands for anabolic substrates than in their ATP requirements (Locasale \& Cantley 2011, Chocarro-Calvo et al. 2013). However, the anabolic urge of tumor cells drives them to adapt with profound metabolic changes, among which the most remarkable is the switch from OXPHOS toward aerobic glycolysis, known since 1956 as the 'Warburg effect' after its discoverer, the Nobel prize-winner Otto Warburg. Glycolysis maximizes the production of building blocks at the cost of diminished energy production compared with OXPHOS. Through glycolysis, cancer cells convert each mole of glucose into 2 mol pyruvate obtaining $2 \mathrm{~mol}$ ATP. Via OXPHOS, $36 \mathrm{~mol}$ ATP are obtained from each mole of glucose. The advantage of glycolytic metabolism is the production of glycolytic intermediaries that can be used in anabolic pathways that allow synthesis of proteins, nucleic acids, and lipids needed for proliferation. Although the Warburg effect was initially observed in rapidly proliferating cancer cells, normal liver cells and highly proliferative $\mathrm{T}$ lymphocytes also exhibit increased glycolysis as a mechanism to maximize the accumulation of anabolic intermediaries required to sustain proliferation (Lunt \& Vander Heiden 2011, MacIver et al. 2013).

An increase in glucose availability that is not contested by storage or the Warburg effect will generally speed up the metabolism, including OXPHOS. This leads to an increase in ROS production, through the mitochondrial respiratory complexes (Balaban et al. 2005) that results in increased DNA damage and cell death (Wellen \& Thompson 2010). Cancer cells increase their glucose uptake and utilization but keep a reduced OXPHOS rate. Increasing glycolysis flux allows enhanced uptake of carbon sources and accumulation of anabolic intermediaries. Decreasing OXPHOS flux declines ROS production which leads to increased cell survival and contributes to sustain pluripotency. Potential mechanisms to decrease ROS in cancer cells and maintain pluripotency are discussed in the next section on 'mechanisms for hyperglycemia increased cancer'. Nevertheless, cancer cells do not completely switch off OXPHOS. The enzymatic machinery is only less efficient due to differential expression of specific enzymatic variants (Balaban et al. 2005).

The apparent paradox that a cancer cell with high energy demands switches toward glycolysis may be interpreted as the adaptation of tumor cells to supply the anabolic intermediates required for rapid proliferation. Therefore, the poor energetic pay off of glycolysis needs to be compensated by a high glucose supply from angiogenesis-derived new blood vessels, high glucose uptake through the upregulation of GLUTs, and increased glycolytic flux through changes in critical enzymes (summarized in Fig. 2).

To keep pace with the increased demand for energy and anabolic intermediates, glucose uptake is enhanced in cancer cells independently of insulin. This is exploited in clinical practice to detect residual tumor activity after surgery through $\left[{ }^{18} \mathrm{~F}\right]$ fluorodeoxyglucose positron emission tomography (FDG-PeT).

GLUTs, and especially GLUT1 whose expression is insulin-independent, are upregulated in many cancer cells (Tennant et al. 2009). GLUTs expression is upregulated by oncogenes such as RAS, hypoxia (via increased activity of the hypoxia inducible factor transcription regulator, HIF1 $\alpha$ ), accumulation of ROS, and other factors characteristic of tumor cells (Cushman \& Wardzala 1980, Suzuki $\&$ Kono 1980). Additionally, HIF1 $\alpha$ cooperates with activated AKT, downstream of PI3K signaling, to enhance the expression of critical glycolytic enzymes (see Fig. 2) such as hexokinase (HK), phospho fructo kinase isoform B (PFKB) (Deprez et al. 1997, Majewski et al. 2004) and lactate

Published by Bioscientifica Ltd. 


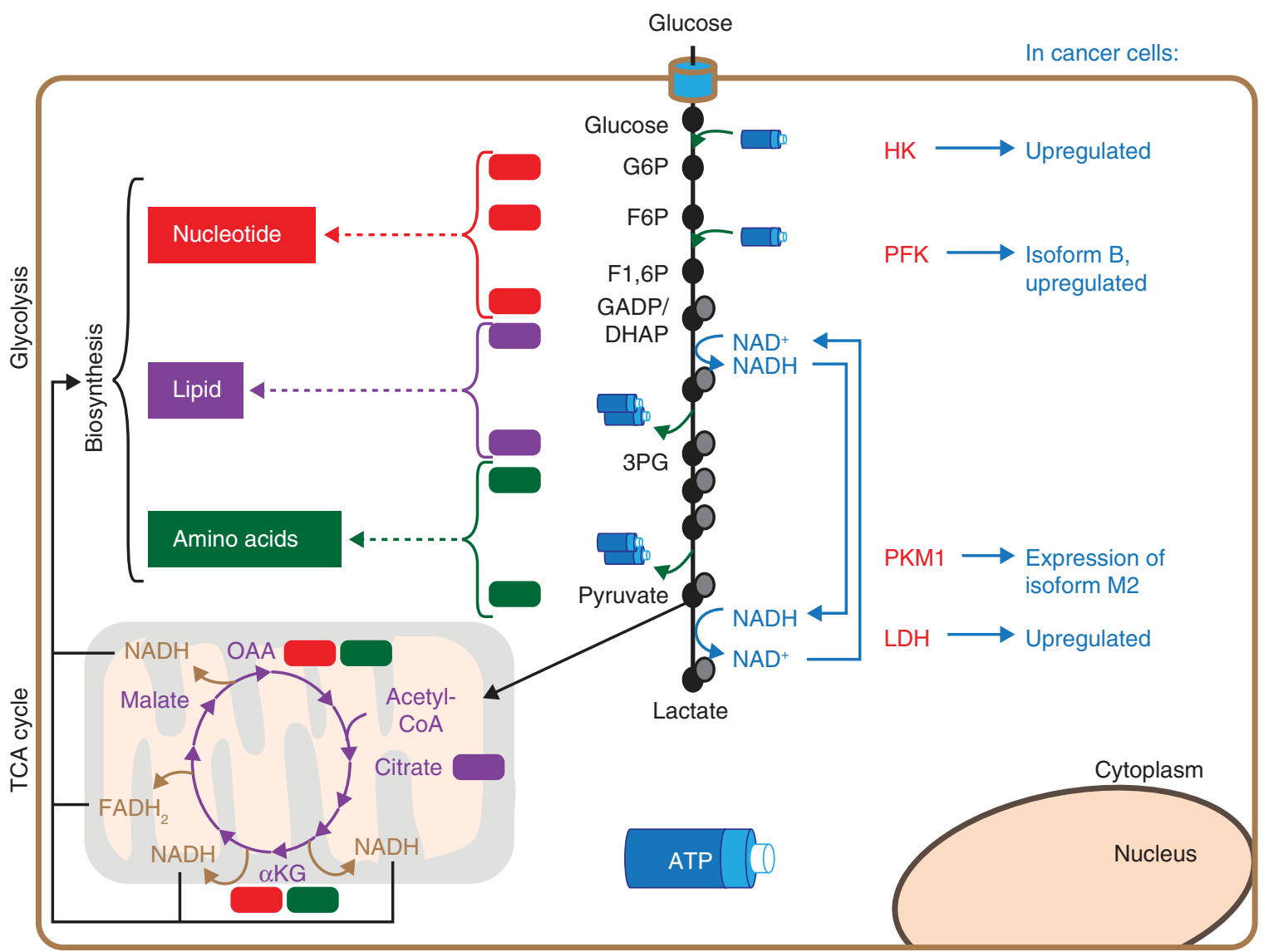

\section{Figure 2}

Gluco-addiction and recycling of glucose into macromolecules to feed proliferation. Of the metabolic adaptations of cancer cells the most remarkable are the increased glycolytic and decreased oxidative phosphorylation (OXPHOS) rates. Although other substrates such as glutamine provide a source of nitrogen and carbon, glucose is the main carbon source and as such uptake of glucose is enhanced by several adaptations. When glucose enters glycolysis, it renders ATP (blue cylinders), redox power (NADH), and, most important for highly proliferating cells, anabolic intermediaries (black dots) ready to use as precursors to synthesize nucleotides (red boxes), amino acids (green boxes), and lipids (purple boxes), which are the building blocks for nucleic acids, proteins, and membranes during proliferation. Increased glycolytic flux is necessary to

dehydrogenase (LDH). LDH reduces pyruvate to lactate and regenerates $\mathrm{NAD}^{+}$. Lactate fuels hepatic gluconeogenesis and $\mathrm{NAD}^{+}$regeneration is critical for continued flux through glycolysis as well as for the deacetylase activity of sirtuins that are critically involved in cancer and longevity. Other glycolytic steps differ in cancer cells due to differential expression of enzyme isoforms. For example, the M2 isoform of pyruvate kinase (PKM2) expressed in cancer cells facilitates diversion of glycolytic intermediates into biosynthetic pathways in contrast with the isoform PKM1, expressed in noncancer cells (Hamanaka \& Chandel 2012). fulfill the increasing demands of proliferating cancer cells which adapt through upregulation of several critical enzymes such as hexokinase (HK), phospho fructo kinase isoform $B$ (PFKB), and lactate dehydrogenase (LDH) which regenerates the $\mathrm{NAD}^{+}$to be used in the next glycolysis cycle and through the expression of characteristic isoform of others like pyruvate kinase, isoform M2 (PKM2) that facilitates the use of glycolytic intermediates in various anabolic pathways. For other details, see the text. AA, amino acid; $\alpha \mathrm{KG}, \alpha$-ketoglutarate; DHAP, dihydroxyacetone phosphate; F1,6P, fructose-1,6-biphosphate; F6P, fructose-6-phosphate; G6P, glucose-6-phosphate; GADP, glyceraldehyde-3-phosphate; OAA, oxaloacetate; 3PG, 3-phosphoglycerate.

\section{Effects of hyperglycemia at the level of the organism and their impact on cancer development}

Hyperglycemia may increase cancer through several cooperative mechanisms, summarized in Fig. 3. We have divided the effects of hyperglycemia on cancer as 'direct' when the effect is exerted directly on tumor cells and 'indirect' when the action takes place at other organs that will later on influence tumor cells. Indirect mechanisms include the induction of i) increased circulating levels of insulin and bioavailability of IGF1, ii) increased secretion

Published by Bioscientifica Ltd 


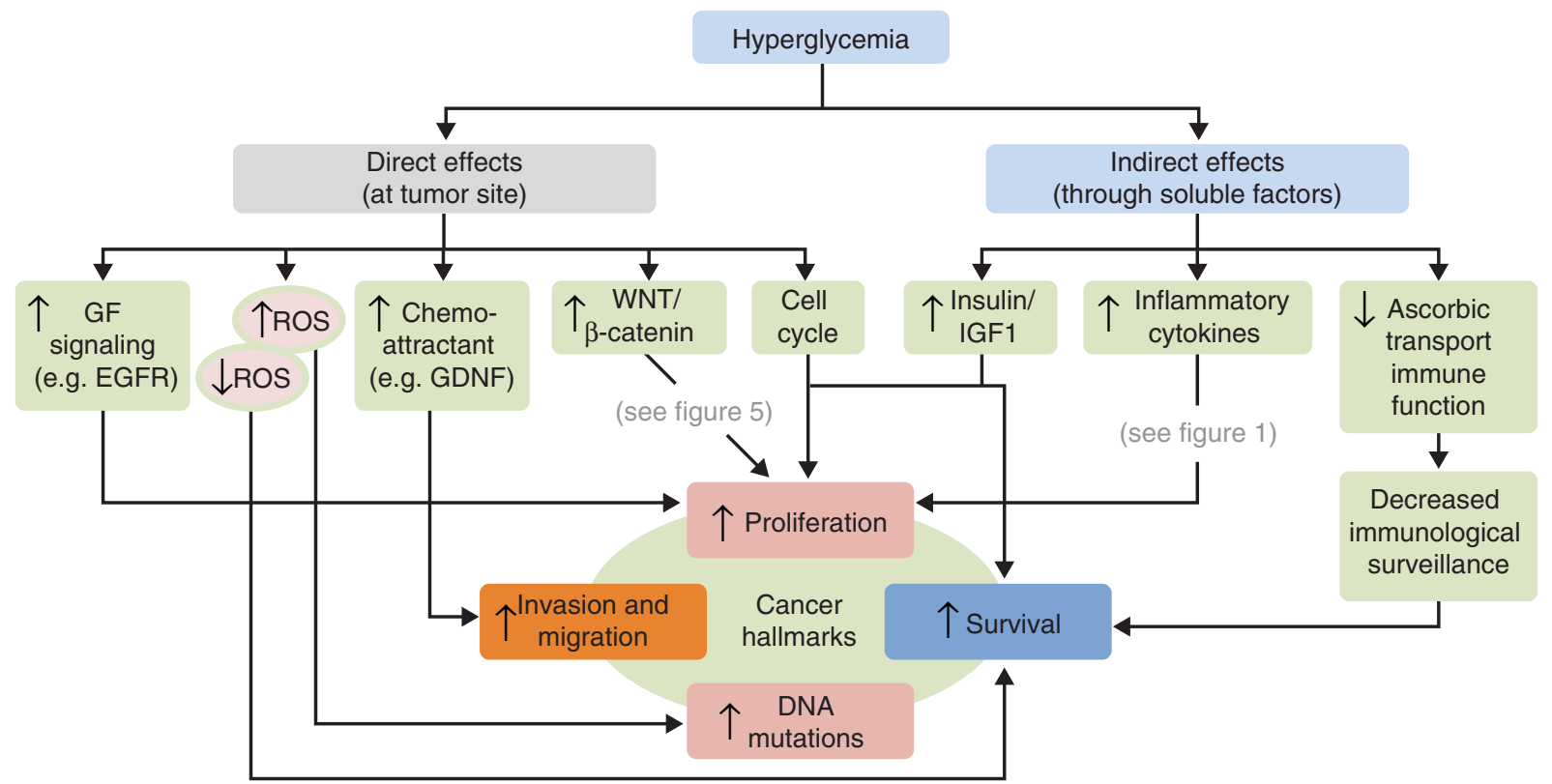

\section{Figure 3}

The many mechanisms by which hyperglycemia may feed cancer cells. Hyperglycemia may have direct effects on the tumor site, or indirect effects through soluble factors. Direct effects promote: i) increased growth factor signaling (GF) and accelerated cell cycle. ii) An initial accumulation of ROS enhances mutagenesis and leads to the secondary selection of clones with diminished ROS production to ensure survival. Alternatively, some cancer cells also export ROS to neighboring cells to ensure their own survival (see the main text). iii) The upregulation of chemo-attractants for invasion, such as glial cell line-derived neurotrophic factor (GDNF). iv) An increase in the WNT/ $\beta$-catenin signaling pathway which favors proliferation,

of inflammatory cytokines and adipokines, and iii) decreased immune surveillance.

First, high plasma glucose concentrations induce insulin secretion and elevate the levels of circulating insulin and free IGF1 (Rajaram et al. 1997), two potent anti-apoptotic growth factors for most cancer cells (Pollak 2008). In addition, insulin also stimulates the release of the proinflammatory cytokine interleukin 6 (IL6) from human adipocytes (LaPensee et al. 2008).

Second, high plasma glucose in vitro and in vivo activates monocytes and macrophages to produce the inflammatory cytokines tumor necrosis factor alpha (TNF $\alpha$ ) and IL6 (Devaraj et al. 2005, Gonzalez et al. 2012). Interestingly, circulating $\mathrm{TNF} \alpha$ and IL6 levels are also increased through a tumor-induced acute phase inflammatory response (McCall et al. 1992) and trigger insulin resistance in cancer patients (Makino et al. 1998). Additionally, the inflammatory process leads to increased gluconeogenesis in the liver of cancer patients, which is further enhanced by lactate secreted from the tumor (Waterhouse et al. 1979; Fig. 4). Hepatic gluconeogenesis antisenescence and invasion. The mechanisms used for high glucose to enhance this pathway are summarized in Fig. 5. Indirect effects of hyperglycemia on cancer cells are mediated through i) increased levels of insulin/IGF1 and/or ii) inflammatory cytokines as well as iii) a diminished immunological surveillance. The reduced immune response is achieved through the reduction in ascorbic acid transport in critical immune cells that diminishes their phagocytic and proliferation capabilities. Both direct and indirect effects converge on cancer hallmarks (increased proliferation, survival, invasion, and migration and accumulation of mutations in the DNA). For other details, see the main text.

increases circulating glucose levels and, consistently, removal of the tumor improves glucose clearance (Permert et al. 1993, Yoshikawa et al. 1994). In summary, high glucose and inflammation feed each other as high glucose triggers inflammation while inflammation induces insulin resistance and hepatic gluconeogenesis, both leading to increased glycemia in a positive feedback loop.

Third, high glucose alters immune function because glucose competitively impairs the transport of ascorbic acid into immune cells (Krone \& Ely 2005). As ascorbic acid is needed for effective phagocytosis, mitosis and for proper function of lymphocytes, the immune response to malignant cells diminishes with hyperglycemia. It stands to reason that all these mechanisms may act synergistically.

Thus, at the level of the organism not only does hyperglycemia enhance tumor growth through several non exclusive mechanisms, but there are also a number of mechanisms by which the tumor induces metabolic adaptations in other organs to favor hyperglycemia. The supply of high glucose to the 'parasite' cancer cells is thus increased. These bidirectional relationships are summarized in Fig. 4.

Published by Bioscientifica Ltd. 

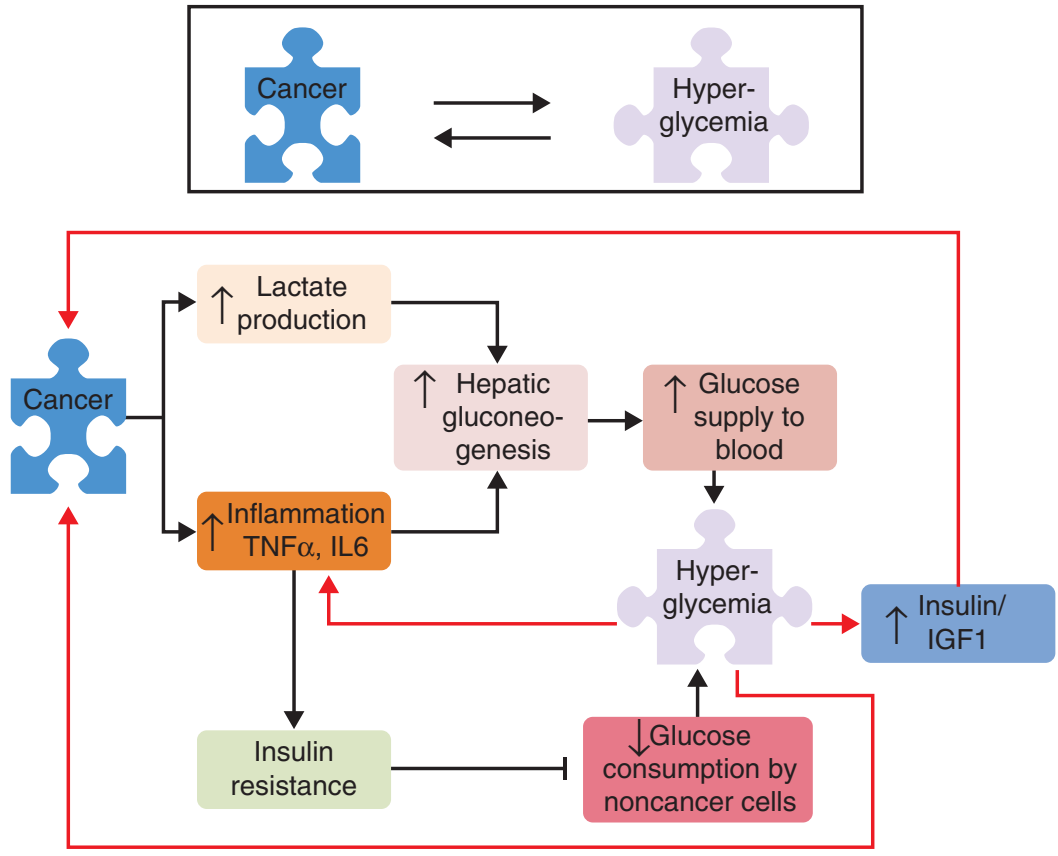

\section{Figure 4}

Cancer cells ensure high glucose supply through enhanced hyperglycemia and hyperglycemia favors tumor growth: the strategy of a parasite. Hyperglycemia favors tumor growth at the organism level - as depicted in 'indirect mechanisms' in Fig. 3 - by increased secretion of the growth factors, insulin and IGF1, reduced immune surveillance, and increased circulating inflammatory cytokines. This causes insulin resistance that diminishes glucose consumption (by noncancer cells) and increased hepatic glyconeogenesis. Reduced uptake from the blood and increased supply

\section{Mechanisms for hyperglycemia increased cancer risk: direct effects on cancer cells}

The direct effects of high glucose on tumor cells include i) increased proliferation, ii) induced mutations, iii) augmented invasion and migration and iv) rewiring of cancer-associated signaling pathways.

First, high glucose accelerates the cell cycle through changes in the expression of critical genes such as E2F and cyclins A and E (Masur et al. 2011). Proliferation is also induced through increased expression of epidermal growth factor (EGF) and enhanced EGF receptor signaling in pancreatic cancer cells (Li et al. 2011).

Second, high glucose induces mutations through upregulated oxidative stress-responsive genes (like thioreodoxin-interacting protein) that in turn increase the levels of ROS (Turturro et al. 2007). ROS facilitate mutations and cell death through increased DNA damage, impaired repair, accumulation of advanced glycation end products (Sindhu et al. 2004) and, as reported in diabetic individuals, through the overproduction of superoxide by from the liver contribute to hyperglycemia. Cancer supports and enhances hyperglycemia in various ways: i) the metabolic switch in cancer cells drives increased glycolytic flux and lactate production. Lactate induces glyconeogenesis at the liver contributing to hyperglycemia. ii) Tumor growth also induces an acute inflammatory response with increased production of inflammatory cytokines TNF $\alpha$ and IL6, known to cause insulin resistance and induce hepatic gluconeogenesis. Both of these processes contribute to hyperglycemia.

the mitochondrial electron transport chain (Brownlee 2001). Unrestricted glucose availability may accelerate the metabolic rate and lead to increased oxygen consumption and ROS generation in a first phase. High ROS will cause mutations first at the mitochondrial DNA (where ROS are produced through OXPHOS) and then in nuclear encoded genes, see Wellen \& Thompson (2010). As most mitochondrial DNA encode for proteins, there will be a high probability that enzymes for OXPHOS will be altered leading to a subsequent decrease in ROS generation. From the generated mutants, those that allow for efficient diversion of captured glucose toward anabolism will be rapidly selected. These include those mutants that render constitutive activation of the AKT signaling pathway and independence of insulin for glucose uptake. Reduction in ROS production will ensure survival and pluripotency of those clones. That is, a switch from high to low ROS production in cancer cells may develop temporarily. Alternatively, ROS produced by cancer cells may be exported to neighboring cells, enabling cancer cells to survive by keeping a low oxidative potential as reported by

Published by Bioscientifica Ltd. 
Martinez-Outschoorn et al. (2013), who used oncogenetransformed cancer cells cocultured with fibroblasts and demonstrated that oxidative stress imposed by oncogene activated cancer cells induces metabolic reprograming toward glycolysis in surrounding fibroblasts, which in turn exported lactate toward cancer cells. Fibroblasts were nesting and protecting the oncogenic cancer cells in a very interesting model of metabolic symbiosis, where the tumor behaves as a parasite (Martinez-Outschoorn et al. 2013). Further research on metabolic interrelationships between cancer and neighboring cells is needed.

Third, high glucose induces invasiveness and migration. Masur et al. (2011) demonstrated that diabetogenic glucose concentrations decrease E-cadherin and increase protein kinase $\mathrm{C} \alpha$ signaling leading to increased cell motility. E-cadherin maintains cell-cell adhesion and plays a pivotal role in epithelial-mesenchymal transition (EMT), a multifaceted developmental program critical for the acquisition of migration and invasion capabilities and for the maintenance of stem cells. EMT might be activated transiently and to different degrees by carcinoma cells during metastasis, reviewed in Hanahan \& Weinberg (2011). Acquisition of EMT phenotype and expression of cancer stem markers were induced in basal luminal breast carcinoma by high glucose consumption which reduced ROS production (Dong et al. 2013) allowing survival. Dong et al. first observed that high glucose induced epigenetic silencing of a critical gluconeogenesis enzyme through the EMT-related transcriptional repressor Snail. Lack of this gluconeogenic enzyme on its own increased glycolysis and the NADPH produced via pentose phosphate pathway (ensuring anabolic intermediates for proliferation) and reduced OXPHOS. Both reduced OXPHOS and increased NADPH (used by enzymes that detoxify $\mathrm{H}_{2} \mathrm{O}_{2}$ ) contributed to lower ROS production, and correlated with expression of cancer stem cell markers dependent on $\beta$-catenin/transcription factor 4 (TCF4) activation, see also comment by Schieber \& Chandel (2013).

In addition to the previous direct effects of high glucose on migration, several diffusible mediators of high glucose also increase migration in the pancreatic cells. For example, high glucose induces the expression of urokinase plasminogen activator. This enhances invasive and migratory activities (Li et al. 2011) and also upregulates chemo-attractant glial cell line-derived neurotrophic factor (GDNF) expression and its interaction with the RET tyrosine kinase receptor, a critical step for tumor progression, migration, and invasion (Liu et al. 2011).

Thus, cancer cell hallmarks concerning glucose metabolism may be consequences and also a cause of transformation (Ward \& Thompson 2012). Oncogenic mutations may dictate increased glucose uptake, which may itself dictate distinct phenotypes inside the tumor, allowing the coexistence of cancer stem and migratory cells as well as highly proliferative cells. Some tumors have been described as symbiotic associations of cells that secrete and cells that import lactate to be used as energy sources (Kennedy \& Dewhirst 2009). The diversity of tumor cells may rely on metabolic differences and on the relationships between tumor cells and their surrounding cells. These are very promising research avenues that will advance our understanding of tumor pathophysiology and may empower therapeutic strategies.

Fourth, high glucose enhances cancer-associated WNT signaling (see below) by allowing nuclear retention and accumulation of transcriptionally active $\beta$-catenin independently of hyperinsulinemia, adipokines, or inflammation (Chocarro-Calvo et al. 2013). $\beta$-catenin is a potent transcriptional coactivator targeted to genes involved in proliferation (Niehrs \& Acebron 2012, Anastas \& Moon 2013) and senescence bypass (Larue et al. 2009) among others. Nuclear $\beta$-catenin is a well-known tumor marker of bad prognosis, and therefore the requirement for high glucose by WNT signaling to promote nuclear accumulation of $\beta$-catenin is likely to have a major impact on cancer biology.

\section{WNT signaling links hyperglycemia and diabetes to cancer}

The WNTs comprise a large family of secreted cys-rich glycoprotein ligands that coordinate cell fate decisionmaking in a broad range of developmental and homeostatic contexts (Clevers \& Nusse 2012). WNT proteins bind to their membrane receptors and activate a number of pathways, including planar cell polarity pathway, $\mathrm{Ca}^{2+}$ signaling, and the canonical WNT/ $\beta$-catenin pathway which is the best known and the most deeply involved in cancer. Functional WNT/ $\beta$-catenin signaling is transiently activated to maintain stem cells in the intestinal crypts (Korinek et al. 1998). However, constitutive WNT signaling was believed to lead to nuclear accumulation of the WNT effector $\beta$-catenin (a well-known tumor marker) and promotion of aberrant cell growth, senescence bypass (Delmas et al. 2007), and cancer (Clevers 2006). Notably, aberrant WNT signaling is present in 40-90\% gastrointestinal cancers (White et al. 2012), which are the specific cancer sites more tightly associated with diabetes.

WNT signaling is also tightly associated with diabetes. Indirect links are illustrated by WNT-regulated control of adipocyte differentiation and obesity (Lu et al. 2013),

Published by Bioscientifica Ltd. 
a major risk factor for diabetes. Direct links are illustrated by the mutations reported in its effector, the transcription factor TCF7L2 (previously known as TCF4), which represent the strongest genetic link with diabetes in all ethnicities (Saxena et al. 2006, Lyssenko 2008). The role of the TCF7L2 intronic mutations associated with diabetes has remained elusive, but since their discovery, WNT/ $\beta$-catenin signaling has been shown to increase the expression of incretin hormones (Garcia-Martinez et al. 2009) that are global regulators of metabolism and are required for normal glucose-dependent insulin secretion. As such, WNT-mediated induction of incretin production established a new link between WNT and diabetes. This has been reinforced by the findings that WNT also induces incretin receptor expression and signaling in the pancreas as well as insulin expression and secretion, reviewed in Garcia-Jimenez (2010). In other tissues, WNT induces the expression of the receptors for insulin and IGF1 (Singh et al. 2013). Recently, Savic et al. (2011) have demonstrated that the diabetes-associated TCF7L2 intronic mutations had a gain of expression effect and a role on glucose metabolism. Next, Boj et al. (2012) demonstrated that most of the genes controlled by TCF7L2 in the liver are metabolic regulators. In fact, the hepatic response to fasting critically relies on TCF7L2. Consistently, hepatic gluconeogenesis is diminished in animals whose TCF7L2 loci have been silenced. Reintroduction of the gene restores glucose production by the liver in concordance with the high blood glucose levels found during fasting in human carriers of the TCF7L2 mutation.

Thus, a growing number of genes involved in metabolism have to be added to the classical WNT/ $\beta$-catenin targets that are mostly involved in proliferation and prosurvival (see below). This suggests that WNT may serve as a new factor that links enhanced cancer risk with metabolic diseases such as hyperglycemia, obesity, and diabetes. This link becomes especially relevant because TCF7L2 mutations associated with diabetes increase basal circulating glucose levels, and because WNT increases insulin production, secretion, and signaling trough enhanced receptor expression.

Excellent and extensive reviews focused on WNT signaling have recently been published (Clevers \& Nusse 2012, Anastas \& Moon 2013), but here we will draw a very simple outline. In the 'cannonical' WNT/ $\beta$-catenin signaling pathway, WNT binds to frizzled and lipoprotein receptor-related protein LRP5/6 coreceptors. This leads to inactivation of glycogen synthase kinase $3 \beta$ (GSK3 $\beta$ ), a kinase that constitutively phosphorylates cytosolic $\beta$-catenin to trigger its degradation.
Traditionally, it was understood that the resulting pool of stabilized cytosolic $\beta$-catenin delocalized from the membrane and entered the nucleus. Once there, it was thought to bind as a potent coactivator to transcription factor members of the $\mathrm{T}$ cell factor/lymphoid enhancer factor (TCF/LEF) family such as TCF7L2 and LEF1, activating target genes which include those of critical factors for proliferation and prosurvival such as those encoding MYC and Cyclin D1. However, there is now new and solid evidence that demonstrates that WNT stimulation alone is not enough to promote nuclear accumulation of $\beta$-catenin, but that this process requires and depends on high glucose to increase its nuclear retention in a variety of human tumor-derived cell lines related to cancers associated with hyperglycemia and diabetes (Chocarro-Calvo et al. 2013). As nuclear accumulation of $\beta$-catenin is a well-known tumor marker of bad prognosis, constitutive WNT signaling in cancer on one side, and increased glucose uptake by tumor cells on the other, reveals a previously unrecognized requisite for WNT signaling in cancer, namely its amplification by high glucose (Chocarro-Calvo et al. 2013). The ability of high glucose to amplify $\mathrm{WNT} / \beta$-catenin signaling provides a link between cancer and hyperglycemia which is independent of inflammation, hyperinsulinemia, or ROS induced mutations. As cancer cells are a well-characterized source of autocrine WNT signaling (Bafico et al. 2004), high glucose uptake may be critical to maintaining nuclear accumulation of $\beta$-catenin and subsequent tumor growth and progression, a notion reinforced by the strong dependence of tumor cells on glucose availability as highlighted above.

\section{High glucose enhances cancer-associated WNT signaling through targeted acetylation of $\beta$-catenin}

High glucose remodels cancer-associated WNT/ $\beta$-catenin signaling to promote the formation and nuclear entry of a LEF1- $\beta$-catenin complex which binds to promoters marked by poised TCF7L2, replacing it and leading to increased expression of WNT target genes (ChocarroCalvo et al. 2013). The model depicted in Fig. 5 summarizes the findings that support this idea. In the absence of WNT and high glucose (left panel), WNT target genes are bound by TCF7L2 and a corepressor complex that silences their expression, while $\beta$-catenin remains associated with the cytoplasmic membrane. High glucose alone (up-right panel) does not increase or de-localize $\beta$-catenin, despite a small increase in p300 levels and WNT-target

Published by Bioscientifica Ltd 


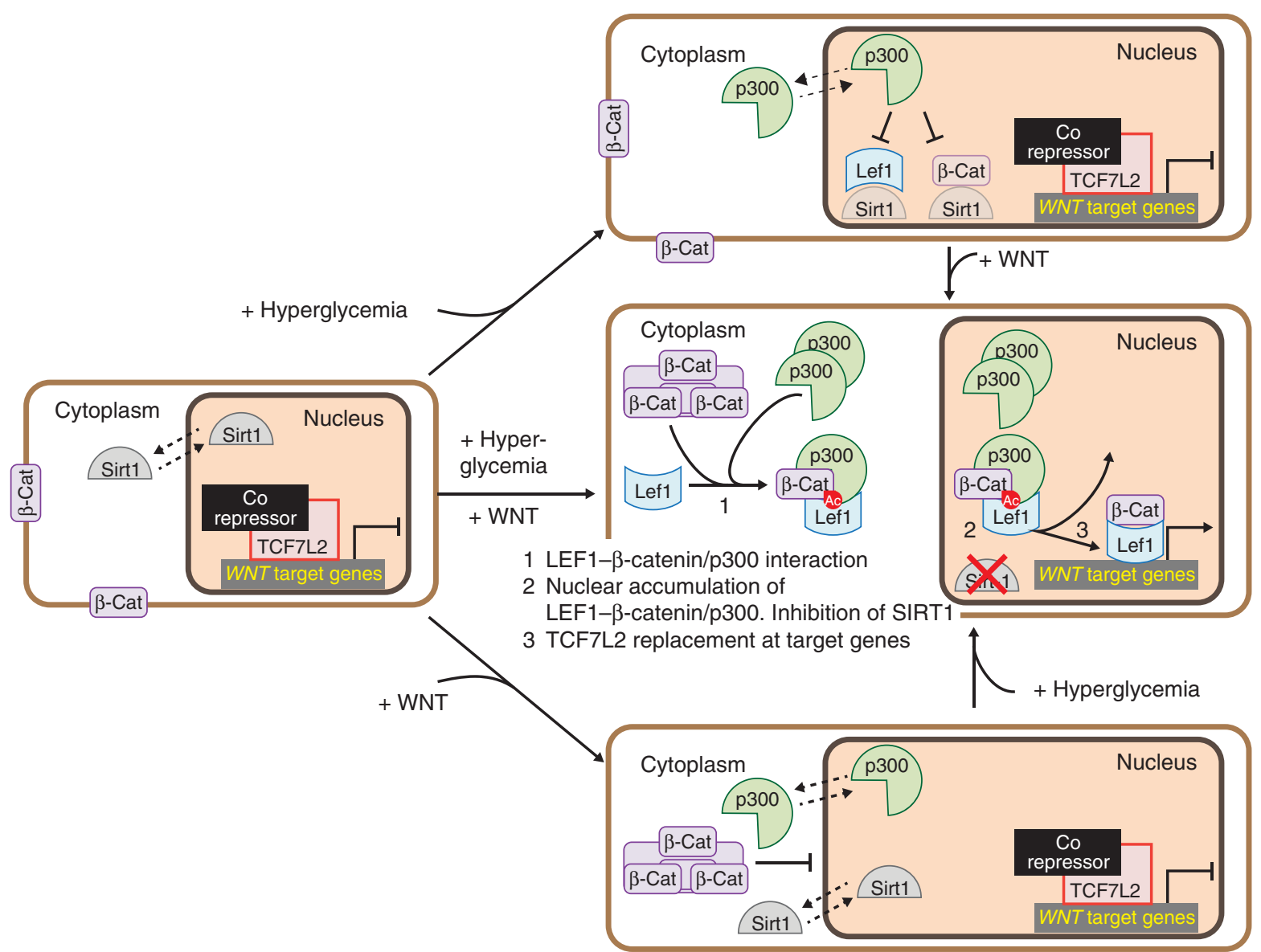

Figure 5

High glucose enhances cancer-associated WNT/B-catenin signaling: a new link between hyperglycemia and cancer. In the absence of high glucose and WNT signals (left panel), WNT target genes remain silenced through targeted binding of TCF7L2-corepressor complexes, and $\beta$-catenin is located at specific plasma membrane sites. Stimulation with high glucose, WNT, or both, is depicted on the right panels. Upon exposure to high glucose (upper-right panel) there is a small accumulation of p300 in the nucleus and cytoplasm, but $\beta$-catenin remains at the membrane and WNT target genes remain silenced. If only WNT signals are present instead of high glucose (bottom-right panel), there is a small increase in p300 and

genes remain silenced. Stimulation by WNT proteins only (bottom-right panel) allows $\beta$-catenin release from the degradation complex and accumulation in the cytosol but not in the nucleus. Coincidence of both signals (right-mid panel) allows high glucose to cooperate with WNT by inducing acetylation of lysine residues in the armadillo repeats of $\beta$-catenin by p300 (whose levels are cooperatively upregulated by WNT and high glucose). This acetylation event is a requirement for LEF1- $\beta$-catenin complex formation, a step that facilitates $\beta$-catenin nuclear entry and specific DNA targeting by LEF1- $\beta$ catenin relying on the exhibition by LEF1 of classical there is accumulation of cytosolic $\beta$-catenin, but nuclear accumulation does not occur and there is no induction of WNT target genes. Upon coincidence of both WNT and high glucose (mid-right panel), the expression of $W N T$ target genes is induced by LEF1- $\beta$-catenin complexes that displace TCF7L2-corepressor complexes. Hyperglycemia acts on cytosolic $\beta$-catenin accumulated via WNT induction to promote three effects: (1) acetylation of $\beta$-catenin that favors formation of LEF1- $\beta$-catenin/p300 complex, (2) inhibition of SIRT1 activity required for nuclear accumulation of LEF1- $\beta$-catenin/p300, and (3) replacement TCF7L2 by LEF1- $\beta$-catenin complex inducing the transcriptional activity of target genes of WNT.

nuclear localization signal and specific DNA-binding domain (both absent in $\beta$-catenin). In this context, the interactions of $\beta$-catenin with TCF7L2 in breast cancer cells have been recently shown to rely on the oxidative state (Dong et al. 2013). High ROS production led to the accumulation of $\beta$-catenin-FOXA3 complexes in detriment of $\beta$-catenin-TCF7L2 complexes and using the antioxidant $N$-acetylcystein or lowering ROS production displaced $\beta$-catenin from FOXA3 toward TCF7L2. In gastrointestinal cancer cells high glucose enhances binding of $\beta$-catenin-TCF7L2 complexes to target genes but the presence of WNT signaling displaces TCF7L2 and favors

Published by Bioscientifica Ltd 
$\beta$-catenin-LEF1 complexes (Chocarro-Calvo et al. 2013). It would be interesting to investigate, in individuals who are carriers of the mutation related to diabetes (that leads to increased expression of TCF7L2 and increased blood glucose), how $\beta$-catenin partnership evolves to adapt to metabolic challenges posed by high glucose and ROS. Also, as acetylation of both histone and non-histone proteins is regulated by nutrients (Wang et al. 2010, Zhao et al. 2010) it would be interesting to explore whether changes in ROS production alters the interactions of $\beta$-catenin with LEF1 and p300.

Earlier studies suggested that overexpressed p300-CBP interacted with the C-terminus of $\beta$-catenin (Hecht et al. $2000)$, leading to lysine acetylation. Binding to TCF-LEF factors (Lévy et al. 2004) and nuclear entry of $\beta$-catenin (Wolf et al. 2002) followed and correlated with increased oncogenic potential (Ma et al. 2005). However, the evidence for a definitive role for p300-mediated acetylation of $\beta$-catenin was inconclusive as mutation of the identified lysine (K345) targeted by p300-CBP did not significantly alter $\beta$-catenin-driven transcriptional activation. The nature of the pathophysiological stimulus that increased acetylation and oncogenic potential also remained unknown. Under WNT signaling, high glucose has been revealed as a pathophysiological stimulus whose combined action, inducing p300 acetyltransferase and inhibiting sirtuin deacetylase activities, targets $\beta$-catenin acetylation. High glucose induced acetylation of lysine K354 in $\beta$-catenin, which induces nuclear retention and transcriptional activation through enhanced p300-LEF1$\beta$-catenin interactions (Chocarro-Calvo et al. 2013).

Interestingly, interaction of SIRT1 with both $\beta$-catenin and LEF-1 is favored by high glucose in the absence of WNT signaling, even though the levels of SIRT1 remain unchanged. During caloric restriction, sirtuin levels are upregulated (Mantel \& Broxmeyer 2008), likely facilitating formation of SIRT1- $\beta$-catenin and SIRT1-LEF1 complexes and outcompeting LEF1- $\beta$-catenin complex formation which is associated with proliferation. In addition, under caloric restriction, there is enough supply of $\mathrm{NAD}^{+}$, as a cofactor needed for sirtuin activity favoring de-acetylation of $\beta$-catenin K354, which diminishes its interaction with LEF1 and transcriptional activity. This hypothetical mechanism would explain the decreased cancer risk associated with calorie-restricted diets. In this scenario, accumulation of $\beta$-catenin in response to WNT signaling and high glucose may outcompete SIRT1 and provide enough $\beta$-catenin to form LEF1- $\beta$-catenin complexes, which will ensure the nuclear accumulation of LEF1- $\beta$ catenin. The low levels of $\beta$-catenin observed in the absence of a WNT signal would be insufficient to activate gene expression even in the presence of glucose as it would not outcompete SIRT1-LEF1 interactions. However, it can be argued that interactions may depend more on protein conformation or exposure of the right domains than on levels, otherwise the most abundant proteins would exhibit the most interactions. A clear example is that upon WNT signaling cytosolic $\beta$-catenin increases but its interactions with E-cadherin are not increased.

Taken as a whole the results by Chocarro-Calvo et al. (2013) suggest that the ability of LEF1 to bind p300 may depend more on stabilizing a conformation through the LEF1- $\beta$-catenin complex (that requires both WNT and glucose), rather than simply relying on p300 levels. Interactions promoted by high glucose upon WNT stimulation (LEF1- $\beta$-catenin with $\mathrm{p} 300$ ) differ from those promoted in its absence (LEF1-SIRT1 and $\beta$-cateninSIRT1), which may appear logical if we consider that WNT imposes dramatic and well-known increases in the availability of $\beta$-catenin. Thus, the combined effect of glucose and WNT on p300 levels and SIRT activity are crucial to shift the balance of acetylation and allow the formation of the LEF1- $\beta$-catenin complex that accumulates inside the nucleus.

The catalytic activity of SIRT1 is important to prevent LEF1- $\beta$-catenin nuclear accumulation and may interfere with LEF1- $\beta$-catenin interactions, or with exposure of the nuclear localization signals, or with nuclear export. Inhibition of sirtuin deacetylase activity mimics glucose-driven nuclear retention of $\beta$-catenin and transcriptional activation in cells where cytosolic $\beta$-catenin has accumulated through WNT-induction (Chocarro-Calvo et al. 2013). Thus, high glucose not only increases p300 levels and acetylase activity but also inhibits sirtuin deacetylase activity, and therefore results in excess acetylation with the consequent transcriptional activation. A possible mechanism for high glucose inhibition of sirtuin activity in the presence of WNT signaling may be given by enhanced glycolysis in tumor cells. Increased glycolytic flux leads to rapid turnover of the $\mathrm{NAD}^{+}$obtained by lactic acid production from pyruvate. $\mathrm{NAD}^{+}$is necessary for the next round of glycolysis, but it is also an essential sirtuin cofactor. Depletion of $\mathrm{NAD}^{+}$then limits its availability for sirtuins and consequently their deacetylase activity. In this respect, it would be interesting to determine the location and activity of sirtuins and of $\beta$-catenin in the subpopulations of cells belonging to the tumor (or the surroundings) that release lactate (generating $\mathrm{NAD}^{+}$) and those that consume lactate (see Martinez-Outschoorn et al. (2013)). Importantly, high glucosemediated amplification of cancer-associated WNT

Published by Bioscientifica Ltd. 
signaling cannot be attributed to nonspecific changes in energy supplies or to a general nutrient requirement because both diabetogenic and physiological glucose concentrations render similar increases in ATP levels having opposite effects on $\beta$-catenin and the use of an alternative carbon source had no effect (Chocarro-Calvo et al. 2013).

\section{Concluding remarks and future perspectives}

The World Health Organization (WHO) predicts that the obese and diabetic population will double from the year 2000 to 2030 and the epidemiological data clearly establish a link between diabetes and cancer. This represents an enormous emotional and financial cost for society and knowledge should guide new policies that maximize prevention and find new treatments at low cost. A close cooperation between epidemiologists, who establish the correlations, and basic scientists, who uncover the mechanisms, may provide the clues to refine and confirm the epidemiological findings and help to implement new policies based on prevention.

There are still many unanswered questions. For example, which WNT signals are required for incretin expression, which WNT signals are released in cancer, and which cooperate with high glucose? When or where is the cancer-related WNT signal released? Are there other signals such as other nutrients, hormones, or cytokines that cooperate with high glucose to induce nuclear accumulation of $\beta$-catenin? Can we find natural metabolites, hormones, etc., that oppose the effects of high glucose on WNT signaling? And if so, would it be possible to direct these signals specifically toward cancer cells and not toward healthy cells? How does glucose alter SIRT1 interactions without altering its levels to promote SIRT1- $\beta$-catenin and SIRT1-LEF1 complexes in the absence of WNT signaling? And how does WNT signaling disrupts these complexes? How can we use the knowledge gained to find new therapeutic targets that explore the ability of diet, hormones, or cytokines to interfere with the acetylation processes specifically in cancer cells? Does glucose impact on other WNT signaling components? How does high glucose impact on other well-known cancer-associated signaling pathways such as MAPK/ERK signaling? Some of these questions are being approached already and others represent new exciting research areas.

Insulin, as a growth factor, has been considered the prime suspect for increased cancer risk in the diabetic population, while metabolic factors have been considered as subordinate modulators of AMPK or mTOR. While the modulation exerted by ROS of both metabolic enzymes and cancer-associated signaling pathways (such as MAPK or PI3K, see Ray et al. (2012)) is widely recognized, little is known about how the metabolic intermediates (for example $\mathrm{NAD}^{+}$levels) may alter cancer pathways such as $\mathrm{WNT} / \beta$-catenin.

We hope that this review will remind the reader that metabolism may drive cancer cell reprograming. During the last international meeting on Prediabetes, much attention was given to the fact that early detection of hyperglycemia and policies that change life style may prevent T2D; perhaps also some cancers might be prevented through the same policies. High glucose amplification of WNT signaling is an example of how metabolism can remodel a cancer-associated signaling pathway. Identifying the molecules and understanding the processes underlying metabolic remodeling of cancer-associated signaling will empower new preventive, diagnostic, and therapeutic approaches toward curing cancer.

\section{Declaration of interest}

The authors declare that there is no conflict of interest that could be perceived as prejudicing the impartiality of the research reported.

\section{Funding}

This work was financed by FIS (PI12/01201). C G-J is professor in Universidad Rey Juan Carlos, J M G-M, and A C-C were supported by teaching contracts from Universidad Rey Juan Carlos (URJC, Madrid). A D V is a researcher and head of Endocrine tumor Unit in the Instituto de Salud Carlos III.

\section{References}

Algire C, Zakikhani M, Blouin MJ, Shuai JH \& Pollak M 2008 Metformin attenuates the stimulatory effect of a high-energy diet on in vivo LLC1 carcinoma growth. Endocrine-Related Cancer 15 833-839. (doi:10.1677/ ERC-08-0038)

Allavena P \& Mantovani A 2012 Immunology in the clinic review series; focus on cancer: tumour-associated macrophages: undisputed stars of the inflammatory tumour microenvironment. Clinical and Experimental Immunology 167 195-205. (doi:10.1111/j.1365-2249.2011.04515.x)

Anagnostou SH \& Shepherd PR 2008 Glucose induces an autocrine activation of the Wnt/ $\beta$-catenin pathway in macrophage cell lines. Biochemical Journal 416 211-218. (doi:10.1042/BJ20081426)

Anastas JN \& Moon RT 2013 WNT signalling pathways as therapeutic targets in cancer. Nature Reviews. Cancer 13 11-26. (doi:10.1038/ nrc3419)

Bafico A, Liu G, Goldin L, Harris V \& Aaronson SA 2004 An autocrine mechanism for constitutive Wnt pathway activation in human cancer cells. Cancer Cell 6 497-506. (doi:10.1016/j.ccr.2004.09.032)

Balaban RS, Nemoto S \& Finkel T 2005 Mitochondria, oxidants, and aging. Cell 120 483-495. (doi:10.1016/j.cell.2005.02.001)

Belfiore A, Frasca F, Pandini G, Sciacca L \& Vigneri R 2009 Insulin receptor isoforms and insulin receptor/insulin-like growth factor receptor 
hybrids in physiology and disease. Endocrine Reviews 30 586-623. (doi:10.1210/er.2008-0047)

Boj SF, van Es JH, Huch M, Li VS, José A, Hatzis P, Mokry M, Haegebarth A, van den Born M, Chambon P et al. 2012 Diabetes risk gene and Wnt effector Tcf712/TCF4 controls hepatic response to perinatal and adult metabolic demand. Cell 151 1595-1607. (doi:10.1016/j.cell.2012. 10.053)

Bosetti C, Rosato V, Buniato D, Zambon A, La Vecchia C \& Corrao G 2013 Cancer risk for patients using thiazolidinediones for type 2 diabetes: a meta-analysis. Oncologist 18 148-156. (doi:10.1634/theoncologist. 2012-0302)

Bowker SL, Majumdar SR, Veugelers P \& Johnson JA 2006 Increased cancer-related mortality for patients with type 2 diabetes who use sulfonylureas or insulin. Diabetes Care 29 254-258. (doi:10.2337/ diacare.29.02.06.dc05-1558)

Brownlee M 2001 Biochemistry and molecular cell biology of diabetic complications. Nature 414 813-820. (doi:10.1038/414813a)

Chen HX \& Sharon E 2013 IGF-1R as an anti-cancer target - trials and tribulations. Chinese Journal of Cancer 32 242-252. (doi:10.5732/ cjc.012.10263)

Chocarro-Calvo A, Garcia-Martinez JM, Ardila-Gonzalez S, De la Vieja A \& Garcia-Jimenez C 2013 Glucose-induced $\beta$-catenin acetylation enhances Wnt signaling in cancer. Molecular Cell 49 474-486. (doi:10.1016/j.molcel.2012.11.022)

Cifuentes M, Garcia MA, Arrabal PM, Martinez F, Yanez MJ, Jara N, Weil B, Dominguez D, Medina RA \& Nualart F 2011 Insulin regulates GLUT1mediated glucose transport in MG-63 human osteosarcoma cells. Journal of Cellular Physiology 226 1425-1432. (doi:10.1002/jcp.22668)

Clevers H 2006 Wnt/ $\beta$-catenin signaling in development and disease. Cell 127 469-480. (doi:10.1016/j.cell.2006.10.018)

Clevers H \& Nusse R 2012 Wnt/ $\beta$-catenin signaling and disease. Cell 149 1192-1205. (doi:10.1016/j.cell.2012.05.012)

Cushman SW \& Wardzala LJ 1980 Potential mechanism of insulin action on glucose transport in the isolated rat adipose cell. Apparent translocation of intracellular transport systems to the plasma membrane. Journal of Biological Chemistry 255 4758-4762.

Dankner R, Chetrit A \& Segal P 2007 Glucose tolerance status and 20 year cancer incidence. Israel Medical Association Journal 9 592-596.

Delmas V, Beermann F, Martinozzi S, Carreira S, Ackermann J, Kumasaka M, Denat L, Goodall J, Luciani F, Viros A et al. 2007 -catenin induces immortalization of melanocytes by suppressing p16INK4a expression and cooperates with N-Ras in melanoma development. Genes and Development 21 2923-2935. (doi:10.1101/gad.450107)

Demetrakopoulos GE, Linn B \& Amos H 1978 Rapid loss of ATP by tumor cells deprived of glucose: contrast to normal cells. Biochemical and Biophysical Research Communications 82 787-794. (doi:10.1016/0006291X(78)90851-3)

Deprez J, Vertommen D, Alessi DR, Hue L \& Rider MH 1997 Phosphorylation and activation of heart 6-phosphofructo-2-kinase by protein kinase B and other protein kinases of the insulin signaling cascades. Journal of Biological Chemistry 272 17269-17275. (doi:10.1074/jbc.272. 28.17269)

Derr RL, Ye X, Islas MU, Desideri S, Saudek CD \& Grossman SA 2009 Association between hyperglycemia and survival in patients with newly diagnosed glioblastoma. Journal of Clinical Oncology 27 1082-1086. (doi:10.1200/JCO.2008.19.1098)

Devaraj S, Venugopal S, Singh U \& Jialal I 2005 Hyperglycemia induces monocytic release of interleukin- 6 via induction of protein kinase $\mathrm{C}-\alpha$ and - $\beta$. Diabetes 54 85-91. (doi:10.2337/diabetes.54.1.85)

Djiogue S, Nwabo Kamdje AH, Vecchio L, Kipanyula MJ, Farahna M, Aldebasi Y \& Seke Etet PF 2013 Insulin resistance and cancer: the role of insulin and IGFs. Endocrine-Related Cancer 20 R1-R17. (doi:10.1530/ ERC-12-0324)

Dong C, Yuan T, Wu Y, Wang Y, Fan Teresa WM, Miriyala S, Lin Y, Yao J, Shi J, Kang T et al. 2013 Loss of FBP1 by snail-mediated repression provides metabolic advantages in basal-like breast cancer. Cancer Cell 23 316-331. (doi:10.1016/j.ccr.2013.01.022)

Dowling RJ, Niraula S, Stambolic V \& Goodwin PJ 2012 Metformin in cancer: translational challenges. Journal of Molecular Endocrinology $\mathbf{4 8}$ R31-R43. (doi:10.1530/JME-12-0007)

El-Mir MY, Nogueira V, Fontaine E, Averet N, Rigoulet M \& Leverve X 2000 Dimethylbiguanide inhibits cell respiration via an indirect effect targeted on the respiratory chain complex I. Journal of Biological Chemistry 275 223-228. (doi:10.1074/jbc.275.1.223)

Fisher WE, Boros LG \& Schirmer WJ 1995 Reversal of enhanced pancreatic cancer growth in diabetes by insulin. Surgery $118453-457$ (discussion 457-458). (doi:10.1016/S0039-6060(05)80358-7)

Gallagher EJ \& LeRoith D 2011 Minireview: IGF, insulin, and cancer. Endocrinology 152 2546-2551. (doi:10.1210/en.2011-0231)

Garcia-Jimenez C 2010 Wnt and incretin connections. Vitamins and Hormones 84 355-387.

Garcia-Martinez JM, Chocarro-Calvo A, Moya CM \& Garcia-Jimenez C 2009 $\mathrm{WNT} / \beta$-catenin increases the production of incretins by entero-endocrine cells. Diabetologia 52 1913-1924. (doi:10.1007/s00125-009-1429-1)

Giovannucci E 2001 Insulin, insulin-like growth factors and colon cancer: a review of the evidence. Journal of Nutrition 131 3109S-3120S.

Giovannucci E, Harlan DM, Archer MC, Bergenstal RM, Gapstur SM, Habel LA, Pollak M, Regensteiner JG \& Yee D 2010 Diabetes and cancer: a consensus report. CA: A Cancer Journal for Clinicians 60 207-221. (doi:10.3322/caac. 20078)

Gnagnarella P, Gandini S, La Vecchia C \& Maisonneuve P 2008 Glycemic index, glycemic load, and cancer risk: a meta-analysis. American Journal of Clinical Nutrition 87 1793-1801.

Gonzalez Y, Herrera MT, Soldevila G, Garcia-Garcia L, Fabian G, PerezArmendariz EM, Bobadilla K, Guzman-Beltran S, Sada E \& Torres M 2012 High glucose concentrations induce TNF- $\alpha$ production through the down-regulation of CD33 in primary human monocytes. BMC Immunology 13 19. (doi:10.1186/1471-2172-13-19)

Graham NA, Tahmasian M, Kohli B, Komisopoulou E, Zhu M, Vivanco I, Teitell MA, Wu H, Ribas A, Lo RS et al. 2012 Glucose deprivation activates a metabolic and signaling amplification loop leading to cell death. Molecular Systems Biology 8 589. (doi:10.1038/msb.2012.20)

Grivennikov SI, Greten FR \& Karin M 2010 Immunity, inflammation, and cancer. Cell 140 883-899. (doi:10.1016/j.cell.2010.01.025)

Haabeth OA, Bogen B \& Corthay A 2012 A model for cancer-suppressive inflammation. Oncoimmunology 1 1146-1155. (doi:10.4161/onci.21542)

Hamanaka RB \& Chandel NS 2012 Targeting glucose metabolism for cancer therapy. Journal of Experimental Medicine 209 211-215. (doi:10.1084/ jem.20120162)

Hanahan D \& Weinberg RA 2011 Hallmarks of cancer: the next generation. Cell 144 646-674. (doi:10.1016/j.cell.2011.02.013)

Hardie DG 2013 AMPK: a target for drugs and natural products with effects on both diabetes and cancer. Diabetes 62 2164-2172. (doi:10.2337/ db13-0368)

Hecht A, Vleminckx K, Stemmler MP, van Roy F \& Kemler R 2000 The p300/CBP acetyltransferases function as transcriptional coactivators of $\beta$-catenin in vertebrates. EMBO Journal 19 1839-1850. (doi:10.1093/ emboj/19.8.1839)

Hellawell GO, Turner GDH, Davies DR, Poulsom R, Brewster SF \& Macaulay VM 2002 Expression of the type 1 insulin-like growth factor receptor is up-regulated in primary prostate cancer and commonly persists in metastatic disease. Cancer Research 62 2942-2950.

Heuson JC \& Legros N 1972 Influence of insulin deprivation on growth of the 7,12-dimethylbenz(a)anthracene-induced mammary carcinoma in rats subjected to alloxan diabetes and food restriction. Cancer Research 32 226-232.

Hoffmann A \& Baltimore D 2006 Circuitry of nuclear factor kappaB signaling. Immunological Reviews 210 171-186. (doi:10.1111/j.01052896.2006.00375.x)

Hsu PP \& Sabatini DM 2008 Cancer cell metabolism: Warburg and beyond. Cell 134 703-707. (doi:10.1016/j.cell.2008.08.021) 
Hummasti S \& Hotamisligil GS 2010 Endoplasmic reticulum stress and inflammation in obesity and diabetes. Circulation Research $\mathbf{1 0 7}$ 579-591. (doi:10.1161/CIRCRESAHA.110.225698)

Ikeda F, Doi Y, Yonemoto K, Ninomiya T, Kubo M, Shikata K, Hata J, Tanizaki Y, Matsumoto T, Iida M et al. 2009 Hyperglycemia increases risk of gastric cancer posed by Helicobacter pylori infection: a populationbased cohort study. Gastroenterology 136 1234-1241. (doi:10.1053/ j.gastro.2008.12.045)

Jee SH, Ohrr H, Sull JW, Yun JE, Ji M \& Samet JM 2005 Fasting serum glucose level and cancer risk in Korean men and women. Journal of the American Medical Association 293 194-202. (doi:10.1001/jama.293.2.194)

Jonasson JM, Ljung R, Talback M, Haglund B, Gudbjornsdottir S \& Steineck G 2009 Insulin glargine use and short-term incidence of malignancies - a population-based follow-up study in Sweden. Diabetologia 52 1745-1754. (doi:10.1007/s00125-009-1444-2)

Jones RG \& Thompson CB 2009 Tumor suppressors and cell metabolism: a recipe for cancer growth. Genes and Development 23 537-548. (doi:10.1101/gad.1756509)

Kalaany NY \& Sabatini DM 2009 Tumours with PI3K activation are resistant to dietary restriction. Nature $\mathbf{4 5 8} 725-731$. (doi:10.1038/nature07782)

Kaplan RC, Buzkova P, Cappola AR, Strickler HD, McGinn AP, Mercer LD, Arnold AM, Pollak MN \& Newman AB 2012 Decline in circulating insulin-like growth factors and mortality in older adults: cardiovascular health study all-stars study. Journal of Clinical Endocrinology and Metabolism 97 1970-1976. (doi:10.1210/jc.2011-2967)

Kasper JS \& Giovannucci E 2006 A meta-analysis of diabetes mellitus and the risk of prostate cancer. Cancer Epidemiology, Biomarkers \& Prevention 15 2056-2062. (doi:10.1158/1055-9965.EPI-06-0410)

Kennedy KM \& Dewhirst MW 2009 Tumor metabolism of lactate: the influence and therapeutic potential for MCT and CD147 regulation. Future Oncology 6 127-148. (doi:10.2217/fon.09.145)

Khandekar MJ, Cohen P \& Spiegelman BM 2011 Molecular mechanisms of cancer development in obesity. Nature Reviews. Cancer 11 886-895. (doi:10.1038/nrc3174)

Klement RJ \& Kammerer U 2011 Is there a role for carbohydrate restriction in the treatment and prevention of cancer? Nutrition and Metabolism $\mathbf{8}$ 75. (doi:10.1186/1743-7075-8-75)

Korinek V, Barker N, Willert K, Molenaar M, Roose J, Wagenaar G, Markman M, Lamers W, Destree O \& Clevers H 1998 Two members of the Tcf family implicated in Wnt/ $\beta$-catenin signaling during embryogenesis in the mouse. Molecular and Cellular Biology 18 1248-1256.

Koroljow S 1962 Two cases of malignant tumors with metastases apparently treated successfully with hypoglycemic coma. Psychiatric Quarterly 36 261-270. (doi:10.1007/BF01586115)

Krone CA \& Ely JT 2005 Controlling hyperglycemia as an adjunct to cancer therapy. Integrated Cancer Therapy 4 25-31. (doi:10.1177/ 1534735404274167)

LaPensee CR, Hugo ER \& Ben-Jonathan N 2008 Insulin stimulates interleukin-6 expression and release in LS14 human adipocytes through multiple signaling pathways. Endocrinology 149 5415-5422. (doi:10.1210/en.2008-0549)

Larue L, Luciani F, Kumasaka M, Champeval D, Demirkan N, Bonaventure J \& Delmas V 2009 Bypassing melanocyte senescence by $\beta$-catenin: a novel way to promote melanoma. Pathologie et Biologie 57 543-547. (doi:10.1016/j.patbio.2008.11.003)

Lasalvia-Prisco E, Cucchi S, Vazquez J, Lasalvia-Galante E, Golomar W \& Gordon W 2004 Insulin-induced enhancement of antitumoral response to methotrexate in breast cancer patients. Cancer Chemotherapy and Pharmacology 53 220-224. (doi:10.1007/s00280-003-0716-7)

Lévy L, Wei Y, Labalette C, Wu Y, Renard C-A, Buendia MA \& Neuveut C 2004 Acetylation of $\beta$-catenin by p300 regulates $\beta$-catenin-Tcf 4 interaction. Molecular and Cellular Biology 24 3404-3414. (doi:10.1128/ MCB.24.8.3404-3414.2004)

Li W, Ma Q, Li J, Guo K, Liu H, Han L \& Ma G 2011 Hyperglycemia enhances the invasive and migratory activity of pancreatic cancer cells via hydrogen peroxide. Oncology Reports 25 1279-1287.
Li J, Cao G, Ma Q, Liu H, Li W \& Han L 2012 The bidirectional interaction between pancreatic cancer and diabetes. World Journal of Surgical Oncology 10 171. (doi:10.1186/1477-7819-10-171)

Liu H, Ma Q \& Li J 2011 High glucose promotes cell proliferation and enhances GDNF and RET expression in pancreatic cancer cells. Molecular and Cellular Biochemistry 347 95-101. (doi:10.1007/s11010010-0617-0)

Locasale JW \& Cantley LC 2011 Metabolic flux and the regulation of mammalian cell growth. Cell Metabolism 14 443-451. (doi:10.1016/ j.cmet.2011.07.014)

Lu H, Ward MG, Adeola O \& Ajuwon KM 2013 Regulation of adipocyte differentiation and gene expression-crosstalk between TGF $\beta$ and Wnt signaling pathways. Molecular Biology Reports 40 5237-5245. (doi:10. 1007/s11033-013-2623-2)

Lunt SY \& Vander Heiden MG 2011 Aerobic glycolysis: meeting the metabolic requirements of cell proliferation. Annual Review of Cell and Developmental Biology 27 441-464. (doi:10.1146/annurev-cellbio092910-154237)

Lyssenko V 2008 The transcription factor 7-like 2 gene and increased risk of type 2 diabetes: an update. Current Opinion in Clinical Nutrition and Metabolic Care 11 385-392. (doi:10.1097/MCO.0b013e328304d970)

Ma H, Nguyen C, Lee KS \& Kahn M 2005 Differential roles for the coactivators $\mathrm{CBP}$ and $\mathrm{p} 300$ on TCF/ $\beta$-catenin-mediated survivin gene expression. Oncogene 24 3619-3631. (doi:10.1038/sj.onc.1208433)

MacIver NJ, Michalek RD \& Rathmell JC 2013 Metabolic regulation of T lymphocytes. Annual Review of Immunology 31 259-283. (doi:10.1146/ annurev-immunol-032712-095956)

Majewski N, Nogueira V, Bhaskar P, Coy PE, Skeen JE, Gottlob K, Chandel NS, Thompson CB, Robey RB \& Hay N 2004 Hexokinasemitochondria interaction mediated by Akt is required to inhibit apoptosis in the presence or absence of Bax and Bak. Molecular Cell 16 819-830. (doi:10.1016/j.molcel.2004.11.014)

Makino T, Noguchi Y, Yoshikawa T, Doi C \& Nomura K 1998 Circulating interleukin 6 concentrations and insulin resistance in patients with cancer. British Journal of Surgery 85 1658-1662. (doi:10.1046/ j.1365-2168.1998.00938.x)

Mantel C \& Broxmeyer HE 2008 Sirtuin 1, stem cells, aging, and stem cell aging. Current Opinion in Hematology 15 326-331. (doi:10.1097/MOH. ob013e3283043819)

Marat D, Noguchi Y, Yoshikawa T, Tsuburaya A, Ito T \& Kondo J 1999 Insulin resistance and tissue glycogen content in the tumor-bearing state. Hepatogastroenterology 46 3159-3165.

Martinez-Outschoorn UE, Curry JM, Ko YH, Lin Z, Tuluc M, Cognetti D, Birbe RC, Pribitkin E, Bombonati A, Pestell RG et al. 2013 Oncogenes and inflammation rewire host energy metabolism in the tumor microenvironment: RAS and NFkB target stromal MCT4. Cell Cycle 12 2580-2597. (doi:10.4161/cc.25510)

Masur K, Vetter C, Hinz A, Tomas N, Henrich H, Niggemann B \& Zanker KS 2011 Diabetogenic glucose and insulin concentrations modulate transcriptome and protein levels involved in tumour cell migration, adhesion and proliferation. British Journal of Cancer 104 345-352. (doi:10.1038/sj.bjc.6606050)

McCall JL, Tuckey JA \& Parry BR 1992 Serum tumour necrosis factor $\alpha$ and insulin resistance in gastrointestinal cancer. British Journal of Surgery $\mathbf{7 9}$ 1361-1363. (doi:10.1002/bjs.1800791240)

Mulholland HG, Murray LJ, Cardwell CR \& Cantwell MM 2008 Dietary glycaemic index, glycaemic load and endometrial and ovarian cancer risk: a systematic review and meta-analysis. British Journal of Cancer $\mathbf{9 9}$ 434-441. (doi:10.1038/sj.bjc.6604496)

Mulholland HG, Murray LJ, Cardwell CR \& Cantwell MM 2009 Glycemic index, glycemic load, and risk of digestive tract neoplasms: a systematic review and meta-analysis. American Journal of Clinical Nutrition 89 568-576. (doi:10.3945/ajcn.2008.26823)

Nakagawa H \& Maeda S 2012 Inflammation- and stress-related signaling pathways in hepatocarcinogenesis. World Journal of Gastroenterology $\mathbf{1 8}$ 4071-4081. (doi:10.3748/wjg.v18.i31.4071) 
Natter K \& Kohlwein SD 2013 Yeast and cancer cells - common principles in lipid metabolism. Biochimica et Biophysica Acta 1831 314-326. (doi:10.1016/j.bbalip.2012.09.003)

Niehrs C \& Acebron SP 2012 Mitotic and mitogenic Wnt signalling. EMBO Journal 31 2705-2713. (doi:10.1038/emboj.2012.124)

Novosyadlyy R \& LeRoith D 2010 Hyperinsulinemia and type 2 diabetes: impact on cancer. Cell Cycle 9 1449-1450. (doi:10.4161/cc.9.8.11512)

Parameswaran N \& Patial S 2010 Tumor necrosis factor- $\alpha$ signaling in macrophages. Critical Reviews in Eukaryotic Gene Expression 20 87-103. (doi:10.1615/CritRevEukarGeneExpr.v20.i2.10)

Park EJ, Lee JH, Yu GY, He G, Ali SR, Holzer RG, Osterreicher CH, Takahashi H \& Karin M 2010 Dietary and genetic obesity promote liver inflammation and tumorigenesis by enhancing IL-6 and TNF expression. Cell 140 197-208. (doi:10.1016/j.cell.2009.12.052)

Permert J, Ihse I, Jorfeldt L, von Schenck H, Arnquist HJ \& Larsson J 1993 Improved glucose metabolism after subtotal pancreatectomy for pancreatic cancer. British Journal of Surgery $\mathbf{8 0}$ 1047-1050. (doi:10.1002/ bjs.1800800841)

Pollak M 2008 Insulin and insulin-like growth factor signalling in neoplasia. Nature Reviews. Cancer 8 915-928. (doi:10.1038/nrc2536)

Pollak M 2009 Do cancer cells care if their host is hungry? Cell Metabolism 9 401-403. (doi:10.1016/j.cmet.2009.04.006)

Priebe A, Tan L, Wahl H, Kueck A, He G, Kwok R, Opipari A \& Liu JR 2011 Glucose deprivation activates AMPK and induces cell death through modulation of Akt in ovarian cancer cells. Gynecologic Oncology 122 389-395. (doi:10.1016/j.ygyno.2011.04.024)

Pylayeva-Gupta Y, Grabocka E \& Bar-Sagi D 2011 RAS oncogenes: weaving a tumorigenic web. Nature Reviews. Cancer 11 761-774. (doi:10.1038/ nrc3106)

Rajaram S, Baylink DJ \& Mohan S 1997 Insulin-like growth factor-binding proteins in serum and other biological fluids: regulation and functions. Endocrine Reviews 18 801-831. (doi:10.1210/er.18.6.801)

Ray PD, Huang BW \& Tsuji Y 2012 Reactive oxygen species (ROS) homeostasis and redox regulation in cellular signaling. Cellular Signalling 24 981-990. (doi:10.1016/j.cellsig.2012.01.008)

Rowlands MA, Holly JM, Hamdy F, Phillips J, Goodwin L, Marsden G, Gunnell D, Donovan J, Neal DE \& Martin RM 2012 Serum insulin-like growth factors and mortality in localised and advanced clinically detected prostate cancer. Cancer Causes \& Control 23 347-354. (doi:10.1007/s10552-011-9883-8)

Santisteban GA, Ely JT, Hamel EE, Read DH \& Kozawa SM 1985 Glycemic modulation of tumor tolerance in a mouse model of breast cancer. Biochemical and Biophysical Research Communications 132 1174-1179. (doi:10.1016/0006-291X(85)91930-8)

Savic D, Ye H, Aneas I, Park S-Y, Bell GI \& Nobrega MA 2011 Alterations in TCF7L2 expression define its role as a key regulator of glucose metabolism. Genome Research 21 1417-1425. (doi:10.1101/gr.123745.111)

Saxena R, Gianniny L, Burtt NP, Lyssenko V, Giuducci C, Sjogren M, Florez JC, Almgren P, Isomaa B, Orho-Melander M et al. 2006 Common single nucleotide polymorphisms in TCF7L2 are reproducibly associated with type 2 diabetes and reduce the insulin response to glucose in nondiabetic individuals. Diabetes 55 2890-2895. (doi:10.2337/db06-0381)

Schieber MS \& Chandel NS 2013 ROS links glucose metabolism to breast cancer stem cell and EMT phenotype. Cancer Cell 23 265-267. (doi:10. 1016/j.ccr.2013.02.021)

Seyfried BT, Kiebish M, Marsh J \& Mukherjee P 2009 Targeting energy metabolism in brain cancer through calorie restriction and the ketogenic diet. Journal of Cancer Research and Therapeutics 5 (Suppl 1) S7-15. (doi:10.4103/0973-1482.55134)
Shikata K, Ninomiya T \& Kiyohara Y 2013 Diabetes mellitus and cancer risk: review of the epidemiological evidence. Cancer Science 104 9-14. (doi:10.1111/cas.12043)

Sindhu RK, Koo JR, Roberts CK \& Vaziri ND 2004 Dysregulation of hepatic superoxide dismutase, catalase and glutathione peroxidase in diabetes: response to insulin and antioxidant therapies. Clinical and Experimental Hypertension 26 43-53. (doi:10.1081/CEH-120027330)

Singh R, De Aguiar RB, Naik S, Mani S, Ostadsharif K, Wencker D, Sotoudeh M, Malekzadeh R, Sherwin RS \& Mani A 2013 LRP6 enhances glucose metabolism by promoting TCF7L2-dependent insulin receptor expression and IGF receptor stabilization in humans. Cell Metabolism 17 197-209. (doi:10.1016/j.cmet.2013.01.009)

Stattin P, Bjor O, Ferrari P, Lukanova A, Lenner P, Lindahl B, Hallmans G \& Kaaks R 2007 Prospective study of hyperglycemia and cancer risk. Diabetes Care 30 561-567. (doi:10.2337/dc06-0922)

Suzuki K \& Kono T 1980 Evidence that insulin causes translocation of glucose transport activity to the plasma membrane from an intracellular storage site. PNAS 77 2542-2545. (doi:10.1073/pnas.77.5.2542)

Szablewski L 2013 Expression of glucose transporters in cancers. Biochimica et Biophysica Acta 1835 164-169.

Tennant DA, Duran RV, Boulahbel H \& Gottlieb E 2009 Metabolic transformation in cancer. Carcinogenesis 30 1269-1280. (doi:10.1093/ carcin/bgp070)

Turturro F, Friday E \& Welbourne T 2007 Hyperglycemia regulates thioredoxin-ROS activity through induction of thioredoxin-interacting protein (TXNIP) in metastatic breast cancer-derived cells MDA-MB-231. BMC Cancer 7 96. (doi:10.1186/1471-2407-7-96)

Wang Q, Zhang Y, Yang C, Xiong H, Lin Y, Yao J, Li H, Xie L, Zhao W, Yao Y et al. 2010 Acetylation of metabolic enzymes coordinates carbon source utilization and metabolic flux. Science 327 1004-1007. (doi:10.1126/ science.1179687)

Wang T, Ning G \& Bloomgarden Z 2013 Diabetes and cancer relationships. Journal of Diabetes [in press]. (doi:10.1111/1753-0407.12057)

Ward PS \& Thompson CB 2012 Metabolic reprogramming: a cancer hallmark even Warburg did not anticipate. Cancer Cell 21 297-308. (doi:10.1016/j.ccr.2012.02.014)

Waterhouse C, Jeanpretre N \& Keilson J 1979 Gluconeogenesis from alanine in patients with progressive malignant disease. Cancer Research 39 1968-1972.

Wellen KE \& Thompson CB 2010 Cellular metabolic stress: considering how cells respond to nutrient excess. Molecular Cell 40 323-332. (doi:10.1016/j.molcel.2010.10.004)

White BD, Chien AJ \& Dawson DW 2012 Dysregulation of Wnt/ $\beta$-catenin signaling in gastrointestinal cancers. Gastroenterology 142 219-232. (doi:10.1053/j.gastro.2011.12.001)

Wolf D, Rodova M, Miska EA, Calvet JP \& Kouzarides T 2002 Acetylation of $\beta$-catenin by CREB-binding protein (CBP). Journal of Biological Chemistry 277 25562-25567. (doi:10.1074/jbc.M201196200)

Yoshikawa T, Noguchi Y \& Matsumoto A 1994 Effects of tumor removal and body weight loss on insulin resistance in patients with cancer Surgery 116 62-66.

Yu H, Pardoll D \& Jove R 2009 STATs in cancer inflammation and immunity: a leading role for STAT3. Nature Reviews. Cancer 9 798-809. (doi:10.1038/nrc2734)

Zhao S, Xu W, Jiang W, Yu W, Lin Y, Zhang T, Yao J, Zhou L, Zeng Y, Li H et al. 2010 Regulation of cellular metabolism by protein lysine acetylation. Science 327 1000-1004. (doi:10.1126/science.1179689)

Zhou W, Mukherjee P, Kiebish MA, Markis WT, Mantis JG \& Seyfried TN 2007 The calorically restricted ketogenic diet, an effective alternative therapy for malignant brain cancer. Nutrition and Metabolism 45. (doi:10.1186/1743-7075-4-5)

Received in final form 15 September 2013

Accepted 18 September 2013

Accepted Preprint published online 18 September 2013 http://jme.endocrinology-journals.org DOI: 10.1530/JME-13-0152
() 2014 Society for Endocrinology Printed in Great Britain 